\title{
Deontología profesional en torno al libro antiguo
}

\author{
Professional deontology regarding old books
}

\author{
Manuel José PedRAZA Gracia \\ Universidad de Zaragoza, Departamento de Ciencias de la Documentación e Historia de la Ciencia, \\ Pedro Cerbuna 12; 50009, Zaragoza, pedraza@unizar.es
}

\begin{abstract}
Resumen
Se analizan algunos principios recogidos en los códigos éticos relacionados con los profesionales del libro antiguo. Se profundiza en los principios deontológicos aplicables al comercio del libro antiguo y a las bibliotecas que poseen fondos históricos. Tanto en lo que se refiere a la actuación de los profesionales que trabajan en ellas como en lo que se refiere a las bibliotecas con sus usuarios y la comunidad a la que sirven.
\end{abstract}

Palabras clave: Códigos éticos. Deontología. Libro antiguo. Bibliotecas históricas. Fondos históricos. Librerías anticuarias.

\section{Introducción}

Los distintos valores de los libros y de los impresos antiguos y raros hacen que estos documentos sean, más frecuentemente de lo que pudiera parecer, objeto de conflicto de intereses (1), pudiendo llegar, determinadas actuaciones que se efectúan sobre ellos a la falta o al delito, cuando se atenta contra esos mismos valores entre los que se destacan de manera muy notable aquellos que se relacionan con la preservación patrimonial (2). Todo ello lleva a la necesidad de que el profesional que se relaciona con estos documentos debe reflexionar sobre su conducta y cómo ésta puede afectar a las personas con las que se relaciona, especialmente porque no siempre se toma consciencia real de lo que pueden afectar determinadas decisiones y actuaciones sobre las personas 0 instituciones con las que se relacionan.

Las relaciones interpersonales que se establecen en torno al libro antiguo pueden ser muy variadas y presentan muchas facetas. El libro antiguo se compra y se vende, se custodia formando parte de un conjunto armónico que constituye la herencia en una biblioteca (pública o privada) o ayuda a conformar su historia, es una parte del patrimonio de una comunidad, es el elemento insustituible del investigador... Esta visión tan variada, la de las distintas facetas de su naturaleza (del objeto documental), presenta

\begin{abstract}
The paper examines certain principles specified in ethical codes related to rare book professionals. It delves into the deontological principles applicable to rare book trade and libraries, regarding both the actions of professionals working with them and the relationship between libraries and the community they serve.
\end{abstract}

Keyworks: Codes of ethics. Deontology. Rare books. Historical research libraries. Historical collections. Antiquarian bookshops.

perspectivas distintas, sujetos diferentes, actuaciones diversas y, lógicamente también, conductas heterogéneas. Tres son, sin embargo, observados desde una configuración amplia, los escenarios en los que el libro antiguo se constituye en la clave de esas relaciones:

1. El libro o impreso antiguo o de valor como mercancía de comercio anticuario. Relación que se produce entre particulares o entre un particular y una institución.

2. El libro o impreso antiguo o de valor como unidad bibliográfica dentro de una colección o fondo. En este caso hay dos perspectivas diferentes por lo que se refiere a las relaciones que se producen:

3. El bibliotecario profesional que trabaja para una institución tanto en su relación frente a la institución como en la relación con los usuarios de la biblioteca.

4. La biblioteca que posee fondos antiguos frente a la sociedad que atiende, frente a los usuarios y frente a los proveedores.

5. El libro o impreso antiguo o de valor como Patrimonio de un pueblo. Cuando el libro o impreso antiguo o de valor forma parte del patrimonio de una comunidad son numerosas las actuaciones que pueden producirse, generalmente tienen que ver con la comercialización, con la preservación, con la difu- 
sión... y siempre deberá actuarse en relación con la salvaguarda del componente patrimonial. Pero no se puede hablar en puridad de una actuación ética o deontológica, porque los aspectos relacionados con la vertiente patrimonial superan el ámbito de los códigos deontológicos entrando en el ámbito de la legislación. La reserva de la disposición del patrimonio para el uso de los ciudadanos contemporáneos y para la memoria de los ciudadanos futuros exige un nivel mayor de protección de estos bienes cuyas actuaciones deben de guiarse por normas emanadas del estado. En efecto, el mundo del comercio, el del coleccionismo, el de los centros y el de los profesionales se ve afectado en sus quehaceres por la legislación patrimonial.

Los profesionales de los libros e impresos antiguos y de valor en sus actividades dentro de los centros se regulan por la normativa general enmarcada en lo administrativo por la legislación de patrimonio y en los aspectos penales por el código penal. El comercio del libro antiguo sigue en lo referente a los bienes patrimoniales idéntica legislación. Por esta causa, este trabajo incide en los dos primeros escenarios mencionados: el comercio del libro antiguo y el de los centros que poseen este tipo de documentos y los bibliotecarios que los atienden en sus relaciones cotidianas, obviando conscientemente el componente patrimonial.

El libro antiguo aporta un conglomerado de factores que hacen de él un elemento complejo en el que, además, muchos de estos factores influyen en alguno de los valores que lo constituyen. Esta complejidad produce un efecto que se ha de considerar como punto de partida: las personas que se acercan a estos materiales suelen ser, si no expertos, buenos conocedores de los materiales que tienen entre manos: piénsese en un librero anticuario, un subastador, un bibliotecario, un bibliófilo, un investigador, un responsable en patrimonio... Todos ellos son perfectos entendidos de lo que comporta cualquier ejemplar que pasa por sus manos o están en condiciones de llegar a conocerlo de forma bastante precisa. Esta circunstancia favorece la existencia de discrepancias y de opiniones no siempre coincidentes.

Entre los mencionados factores, no son, en absoluto, insubstanciales los meramente materiales que son observados por una línea nada desdeñable de la investigación como una vía para llegar hasta la intención del autor de los contenidos con respecto a estos (3). Se trata de materiales que tienen que ser apreciados desde un punto de vista global sin despreciar ninguno de sus componentes. Es especialmente remar- cable el hecho de que, cuando de libro antiguo se trata, no se produce de forma principal un problema ético con respecto a la información que contiene (que también) (4), sino, con mucha más frecuencia, los problemas en los principales ámbitos en los que se producen, lo hacen por encontrarse discrepancias ante el documento en sí mismo pesando de forma particular la vertiente material (5).

El libro antiguo suele ser un producto de precio elevado. En el establecimiento del precio intervienen ingredientes de todo tipo intrínsecos y extrínsecos y entre los primeros, los hay referidos a la edición o variante y los referidos al ejemplar. Este gran conglomerado de factores favorecen también las discrepancias en cuanto al establecimiento de un precio. Y si de la transacción de libros antiguos se trata, las relaciones comerciales también son factores en los que los contrastes de pareceres surgen con facilidad. Es de remarcar que precisamente las discrepancias sobre el precio establecido no están sujetas a normas deontológicas, ya que caen dentro de la libertad que poseen las partes que intervienen en el negocio jurídico para establecer un precio y para aceptarlo o no.

\section{Aspectos y códigos deontológicos en torno al comercio del libro antiguo}

El libro antiguo desde la perspectiva comercial es un objeto de valor económico contrastado, una mercancía que está sujeta a la ley de oferta y demanda. En este mundo las relaciones humanas en torno a estos objetos que pueden alcanzar precios muy elevados pueden conducir a actuaciones en las que las posiciones morales entren en contradicción. Esta circunstancia ha favorecido que las propias asociaciones de libreros anticuarios hayan elaborado sus propios códigos deontológicos con los que las librerías anticuarias definen los usos universalmente aceptados y aplicables a todas las transacciones comerciales entre libreros o entre los libreros y las instituciones o los individuos particulares. El principal es el de la International League of Antiquarian Booksellers (ILAB) (6). Para el caso español existe el redactado por Asociación de Libreros de Viejo y Antiguo de Castilla y León (ALVACAL) para sus asociados y que también es aceptado por los participantes en el portal de librerías librerosdeviejo.com (7). En general se trata de una adaptación bastante aproximada del Código de la ILAB, aunque con algunas diferencias notables.

Los objetos a los que hace referencia este código son: libros, manuscritos, cartas autógrafas, 
grabados, mapas y dibujos, y cualquier otro tipo de documento impreso o manuscrito.

No se debe perder de vista que en el mundo del comercio del libro e impreso antiguo no se negocia con ediciones, sino con ejemplares. Esta particularidad hace que esta actividad sea bastante más compleja que el comercio del libro nuevo en general, porque los ejemplares desde que salen del taller del impresor y, especialmente, cuando trascurre un tiempo adquieren por adición de características positivas y negativas o por sustracción de elementos originales una singularidad que los individualiza del resto de los ejemplares de la misma edición y variante. Baste con indicar que la elección de la encuadernación hasta el siglo XIX corresponde al propietario (cualquiera de los sucesivos poseedores), que suele comprar el libro en rama en la librería y dejarlo al propio librero para que lo encuaderne a gusto del comprador, con lo cual tendrá las características que el propietario le indicase al librero (que es en puridad el fabricante de libros). De esta manera, además de la primera encuadernación, el propietario del siglo XVI o del XVIII habrá dejado su ex-libris en el ejemplar de su propiedad mediante una indicación manuscrita o con una etiqueta pegada, un lector del XVII pudo incluir anotaciones manuscritas en los márgenes que añaden nuevos contenidos científicos aportando una mayor calidad de contenidos superior a cualquier otro ejemplar...(8) $\mathrm{O}$, por el contrario, la desidia de un poseedor del XIX dejó que el libro fuera atacado por roedores o bibliófagos, dejó que fuese empleado para escribir garabatos por niños o usado para secante de moldes de impresión de telas, dejo que los hongos atacaran el papel o la encuadernación y le recorto o eliminó las ilustraciones para decorar otros documentos, o que muchas de sus hojas fuesen empleadas para confeccionar cartuchos o papeletas para envolver productos, dejando el libro prácticamente inutilizable. Pudo ocurrir que, durante un conflicto bélico, fuese utilizado como parapeto $y$ todo ello tras pasar por las manos de un inquisidor de feroz tachadura... que dejó su nombre y fecha en la nota de la censura. Pudo ocurrir que un propietario reprodujera las hojas desaparecidas con la máxima precisión y las incorporara de nuevo al ejemplar o las extrajera de otro ejemplar de la edición o de una edición diferente del mismo o de otro impresor para completar su ejemplar (9), y que retirara una encuadernación de abanicos sobre una piel de gran calidad por parecerle recargada y le pusiese una contemporánea de materiales sintéticos o que buscando una encuadernación contemporánea del libro forzase un remboîtage...(10) Como puede verse, en cada uno de los ejemplares han podido incidir los gustos y los intereses de sus propietarios, poseedores y lectores y otras muchas circunstancias ajenas al uso normal del libro y cada uno de los ejemplares de la edición de la misma variante habrá llevado una "vida" con unos acontecimientos diferentes de los del resto, dando lugar a un documento con unas características materiales singulares. Ni que decir tiene que esta singularidad se lleva al extremo cuando se trata de manuscritos, de los únicos ejemplares conocidos de una edición o de los restos fragmentarios del único ejemplar conocido de la edición; aunque, en estos dos últimos casos, siempre quedará la posibilidad y la esperanza de encontrar otros ejemplares de esa misma edición...

\subsection{Para empezar la identificación y, consecuentemente, la descripción}

La identificación es, sin duda, la actividad eje sobre la que el mundo del comercio hace girar su negocio. Siempre que se trata de libro antiguo resulta capital proceder a una identificación lo más precisa posible del documento. La corrección en esa identificación es la que propicia una descripción acertada. El librero puede confundirse a la hora de tasar un libro (normalmente se juega su patrimonio en ello), pero de ninguna manera lo que puede es errar en la descripción que proporciona del documento o, mediante las indicaciones que proporciona, llevar a confusión al posible comprador del mismo por una incorrecta identificación (Clavería, 2002, p. 176). La identificación es múltiple ya que no solamente hay que reconocer el contenido; hay que examinar también el resto de los factores que constituyen el documento, dando lugar a diversas identificaciones (del impresor o del editor, del encuadernador...) entre las que no es desdeñable la identificación de la integridad documental, bien sea por registrar carencias con respecto a su edición o variante, ser un mútilo, o por estar compuesto por más de un ejemplar conformando un volumen facticio.

Es imprescindible indicar no sólo las bondades del documento, sino también todos aquellos defectos o desperfectos que posea: los ataques de bibliófagos y hongos, manchas, márgenes recortados, rasgaduras que afecten o no afecten al texto... Todos ellos descritos de la manera más concreta, correcta y exhaustiva posible. El problema de la terminología utilizada en las ofertas de venta en bases de datos y catálogos para estas indicaciones y para otras no es intrascendente, ya que tiene que ser perfectamente comprendida por los posibles compradores $\mathrm{y}$, en la medida de lo posible, avalada por el uso dentro del comercio. Igualmente es imprescindi- 
ble indicar todas las ausencias; las páginas que puedan faltar, incluidas las hojas en blanco, las láminas que hayan podido desaparecer del ejemplar. $Y$ todo ello se ha de poner de manifiesto de forma evidente, no basta con indicar lo que el documento posee, si no se menciona, además, lo que le falta y debería poseer. La mera descripción resulta, por esta causa, claramente insuficiente.

También hay que indicar las restauraciones y cualesquiera otras intervenciones realizadas sobre el ejemplar, del tipo que sean: tanto las modificaciones de carácter positivo como aquellas que intencionadamente, o no, inciden de forma negativa, en los valores del documento.

Todas estas menciones, advertencias y explicaciones se han de llevar acabo tanto sobre el material impreso o manuscrito como sobre la encuadernación y sobre la unión entre ambos.

Es preceptivo establecer la edición a la que pertenece el ejemplar $y$, cuando se trata de ejemplares de cierta antigüedad, se deben citar los repertorios bibliográficos que mencionan otros ejemplares de la edición, variante o del propio ejemplar en cuestión. No es infrecuente que algunos ejemplares, por la procedencia de los mismos o por sus características, sean conocidos por sus poseedores adquiriendo nombre propios en el mundo del coleccionismo y de la bibliofilia. Esta circunstancia es especialmente aplicada a los manuscritos, aunque también se aplica a algunos ejemplares impresos. Por ejemplo: el Codex Hammer,(12) entre los manuscritos, o el Vesalio de Carlos V (13), entre los impresos.

Esta labor descriptiva requiere un conocimiento profundo de los materiales y herramientas para la identificación que van a favorecer el conocimiento de la edición, permitiendo tener constancia de las características de la misma y las posibles variantes que se hubiesen podido producir. No basta con describir lo que se tiene delante, no es suficiente con indicar que el ejemplar posee diez grabados en madera de perfecta factura (no siendo incorrecta esta información puesto que los contiene, en efecto), cuando tendría que constar que debería de tener once y precisar, sin lugar a dudas, que carece de uno de ellos.

De la misma manera, es imprescindible definir las características con la máxima precisión, por lo que no es suficiente con indicar que la encuadernación está algo fatigada, cuando el desperfecto es notorio por estar rasgada la piel (más que fatigada estaría exhausta). Este tema, junto con el de la terminología, no son aspectos que se puedan dejar al gusto de cada librero, la terminología empleada, técnica y descriptiva, es en extremo importante y debe de ser utilizada de forma rigurosa.

Entre los aspectos que la descripción debe dejar claros está, por su trascendencia, el de la autenticidad. Los libros que se ofertan en venta deben de ser auténticos en todo y en sus partes o debe indicarse con claridad en la descripción la parte o partes que no correspondan al libro original, independientemente del método utilizado para restaurar la integridad o en la falsificación. Aunque existen casos en los que todo el documento es falso (el llamado caso Hofmann y el impreso The Oath of a Freeman es quizás el más conocido por lo que tiene de morboso y de novela negra y macabra) (14); por lo general, las falsificaciones se producen por el intento de completar un mútilo con objeto de hacerlo pasar por un ejemplar íntegro. Esta falsa integridad se puede obtener de diversas maneras: creando un ejemplar completo a partir de dos mútilos de la misma edición o de distinta edición del mismo o de impresor diferente; o, simplemente, confeccionando una reproducción facsimilar de la parte que falta a partir de un ejemplar que la posea, bien sea de forma que se la identifique sin dificultad o bien sea intentando ocultar la inclusión del elemento extraño (15), envejeciendo los papeles y las tintas o utilizando papel de época... Ha de ponerse de manifiesto que algunas de estas actividades no se efectúan de forma dolosa sino que responden a un deseo de logar una integridad por parte del propietario del documento que no siempre quedo suficientemente manifestada en el ejemplar o en la documentación de acompañamiento. En cualquiera de los casos, las dudas sobre la autenticidad del documento deben interrumpir el proceso de puesta en venta del mismo hasta que ese particular no quede perfectamente establecido.

Es también un fenómeno corriente la existencia de ejemplares que por su contenido (generalmente iconográfico) o por componer junto con otros un volumen facticio pudieran ser susceptibles de ser disgregados para su venta por separado. Esta práctica, que suele resultar muy rentable, es contraria a la ética profesional en la librería. En el primero de los casos se destruye la integridad del ejemplar que por ser más costoso tendrá menor salida $y$, en el segundo, se destruye la posibilidad del estudio e investigación del facticio y el análisis de su procedencia (16). Ya se ha hablado de la importancia que para estos documentos tienen los avatares que sufren con el transcurso del tiempo, pero nunca será suficientemente remarcada la trascendencia que tiene el conocimiento de esa evolución, la vida del ejemplar, y su procedencia que su- 
ponen un valor añadido sobre el mismo llevando al ejemplar a una individualización plena.

Siempre que se detecte un error en la identificación y, consecuentemente, en la descripción del documento, las devoluciones del libro al proveedor y de la cantidad abonada por el comprador deben de ser facilitadas al máximo. La intención de proceder de esta manera debe ser manifestada lo más rápidamente posible y llevada a cabo con la misma celeridad.

\subsection{En segundo lugar, el precio}

El precio es la cantidad económica que pactan las partes a cambio de un objeto o servicio, siendo perfectamente conocedoras de todas las características del objeto en cuestión en un momento dado. Generalmente lo que ocurre es que una de las partes establece un precio (cantidad económica) sobre un objeto en un momento anterior al negocio jurídico y otra persona considera aceptable ese precio en el momento en el que lo adquiere. Esta situación se presenta frecuentemente en el mundo del comercio del libro antiguo en el que un comprador acepta el precio marcado por un librero anticuario sobre un libro o impreso, en un catálogo, o en una feria, o salón o en la propia librería; este precio debe estar especificado en el libro en cuestión o en el catálogo. Pero también es frecuente que el comprador establezca el precio por el desconocimiento del valor económico del objeto puesto en venta por parte del vendedor, lo que ocurre a menudo cuando un propietario de un libro que supone posee cierto valor económico acude a un profesional de la librería con la esperanza de que, además de indicarle un precio, lo adquiera. Sobre esta circunstancia incide de forma evidente la ética del profesional resultando evidente que el profesional está obligado a establecer un precio ajustado al mercado, independientemente de que trate como vendedor con un cliente o como comprador con un proveedor y de los conocimientos que posea la otra parte. Por esta misma causa, la indicación del precio debe estar clara tanto en los catálogos, bases de datos o sedes web como en los propios documentos; no se deben utilizar palabras clave que permitan modular el precio en función de las capacidades del cliente (17). Pero, de la misma manera, no se debe olvidar que el precio tiene una vigencia temporal por lo que el precio ofertado no es válido indefinidamente. No es posible exigir que se mantenga un precio después de trascurrido un tiempo que supere lo prudencial.

Entre libreros se mantiene un descuento de cortesía del 10 por ciento que se hace extensible a algunos trabajadores de librerías anticuarias.
Esta cortesía, que viene reflejada en los propios códigos deontológicos internacionales, se viene apartando de la práctica profesional cada vez más debido a la aparición de nuevos profesionales de la librería que llevan a cabo su actividad exclusivamente desde Internet y que no son considerados como miembros de la comunidad que ha generado el propio código deontológico.

\subsection{Las relaciones comerciales, por último}

Las relaciones comerciales se basan en la confianza y el acuerdo. Estos principios deben de estar presentes en este tipo de relaciones por lo que el vendedor debe ofertar y almacenar libros de su propiedad o propiedad reconocida, en ningún caso pondrá en venta ni almacenará libros robados o de procedencia dudosa; asimismo, ha de comprometerse a colaborar con las autoridades para solventar cualquier duda sobre la propiedad de ejemplares que le sean ofrecidos o que él mismo haya puesto en venta desconociendo la procedencia ilícita de los mismos. Es obvio que en estos supuestos se supera el ámbito ético entrando en el ámbito delictivo. De aquí se deduce que es el librero vendedor el que se responsabiliza de comprobar y buscar la justificación de la propiedad de los libros aportados por los proveedores de la librería.

Evidentemente, una vez efectuada la compraventa, el vendedor debe recibir el pago por el total de los bienes entregados y el comprador recibir todos los bienes adquiridos en el estado en que los compró. Por su parte, el comprador no debería anular un pedido porque no se le puedan entregar todos los ejemplares solicitados en un pedido múltiple, por estar ya vendidos algunos de ellos, por ejemplo; siempre que no se haya estipulado así de antemano entre las partes.

Los daños (o las pérdidas) ocurridos durante el transporte corresponden al remitente que debe garantizar una cuidadosa manipulación, embalaje, envío y unos correctos materiales de transporte. El fin es que el comprador reciba los libros adquiridos en la misma condición que cuando los compró. En el caso de envíos a examen, se debe de determinar un periodo para que los libros estén en manos del comprador potencial; trascurrido el cual la venta se considera cerrada por parte del vendedor. Los gastos de envío corresponden a la parte que solicita la revisión del libro y, en caso de devolución, éste mismo es el responsable de los desperfectos ocurridos mientras los libros estén en su poder.

Además de la actuación considerada normal en la librería, la compraventa de libros antiguos, los libreros anticuarios realizan también otras acti- 
vidades comerciales de carácter técnico y de representación. Una de esas labores principales es la de efectuar tasaciones. Otra de las actuaciones es la representación en subastas, en este tipo de funciones representativas los libreros deben, en primer lugar, examinar los lotes para evitar problemas con los mandantes y, en segundo lugar, pactar con ellos una comisión, que se encuentra habitualmente en torno al diez por ciento. Estas actuaciones deben ser escrupulosas con las estimaciones de los precios y con la advertencia del cumplimiento de la legislación económica y patrimonial que corresponda. No entra dentro de la actividad del librero anticuario ni se considera ético el recomendar a sus clientes el libro antiguo como bien de inversión ya que no es experto en estas funciones de carácter económico-financiero.

\section{Aspectos y códigos deontológicos en torno al bibliotecario de fondo antiguo}

El bibliotecario de fondos antiguos tiene una doble responsabilidad ante los usuarios y ante la biblioteca o la entidad a la que pertenece la biblioteca. Esta doble situación conduce a que el bibliotecario no debe, con sus acciones, influir en la pérdida de confianza del usuario en la biblioteca y en la confianza de la institución en el trabajo del bibliotecario, de forma que no se comprometa a la institución con las actuaciones del bibliotecario.

El principal de los códigos deontológicos dedicados a los bibliotecarios y bibliotecas de fondo antiguo es el publicado por la Association of College and Research Libraries (18). Han sido traducidas al castellano bajo el título Normas de Conducta Ética para Bibliotecarios de Libros Raros, Manuscritos, y Fondos Especiales, con Directrices para la Práctica Institucional en Apoyo de las Normas, $2^{a}$ edición, 1992 por el Grupo de Trabajo sobre Patrimonio Bibliográfico de REBIUN (19).

Este código considera conveniente y aconsejable que los bibliotecarios de fondos antiguos 0 especiales mantengan también actividades académicas, profesionales y personales, pero siempre que se tenga presente que esas actividades no deben entrar en colisión con las actividades que realizan en la biblioteca que deben ser llevadas a cabo completa y concienzudamente; por consiguiente, cualquier actividad externa debe ser compatible con el trabajo que se realiza en la biblioteca. En el ejercicio de esas actividades se debe evitar cualquier conflicto de intereses y el uso indebido del nombre de la biblioteca, de tal manera que se desprestigie su nombre o el patrimonio de la misma. Por consiguiente, parece conveniente realizar las consultas pertinentes ante la institución en la que se prestan servicios antes de utilizar su nombre a la hora de llevar a cabo cualquier actividad académica o profesional. Si bien no se trata de un principio aplicable de forma específica a los bibliotecarios de fondos antiguos y especiales, debido a la especialización que adquieren estos profesionales con este tipo de documentos son frecuentemente llamados para ejercer actividades de consulta y de formación, por lo que se deben prestar especial atención a estas recomendaciones.

\subsection{El bibliotecario coleccionista}

El coleccionismo particular de documentos por parte de los bibliotecarios no se considera una actividad inmoral, de hecho este tipo de actividad puede favorecer la formación del bibliotecario. El problema se establece cuando la colección particular y la de la institución coinciden en su composición. Es evidente que cualquier bibliotecario puede poseer, como cualquier ciudadano, una colección de libros privada; el coleccionismo privado de libros antiguos y de valor, sin perjuicio de la libertad que todo ciudadano posee para mantener actividades privadas de coleccionismo bibliográfico, puede plantear algunos conflictos, frecuentemente más estéticos que éticos. Normalmente el sentido común dicta formas de actuar que hagan que no tenga por qué haber conflictos en esa situación, pero la posibilidad de que los haya ha de ser suficiente como para que se eviten algunos posibles como: la competencia entre el bibliotecario y la biblioteca ante la compra de un ejemplar en una subasta, o que puedan plantearse dudas sobre la propiedad en una venta, o que para investigación personal o cualquier otra causa se puedan llevar libros de la colección propia a la biblioteca sin haber sido inspeccionados a la entrada y salida siendo perfectamente identificados para evitar cualquier duda sobre la propiedad, por ejemplo... En principio, cualquier duda sobre la preferencia queda solventada si las necesidades de la biblioteca son atendidas con prioridad sobre las de la propia colección; por ejemplo, en un conflicto sobre una adquisición. Otros conflictos se solventan fácilmente con la mera aportación de la información necesaria (transacciones que se realiza o se piensa realizar) por parte del bibliotecario coleccionista a la institución en la que trabaja; o al comprador, cuando actúa como vendedor, sobre la propiedad inequívoca de los libros que vende (mediante una declaración jurada, por ejemplo). Quizás, uno de los aspectos que menos dudas éticas puede comportar es el de la aceptación de rega- 
los o descuentos en las adquisiciones propias cuando se adquieren ejemplares para la biblioteca. La buena práctica ética exige que estos regalos y descuentos deban de ser rechazados.

\subsection{El bibliotecario comerciante de libros}

El bibliotecario de fondo antiguo debería de abstenerse de realizar actividades relacionadas con el comercio del libro en las que la biblioteca se vea involucrada y por las que el bibliotecario obtenga un lucro personal, sea del tipo que sea, porque es evidente que esta actividad entra en colisión con los intereses de la biblioteca. Cuando se acuda al técnico de la biblioteca, como tal, y existan intereses por su parte, deberá de abstenerse en la recomendación de adquisición o en participar en otras actividades comerciales bien se trate de una adquisición, de una venta o de otra transacción. Es indudable que esta actividad llevada a cabo sin perjuicio de los intereses de la biblioteca, sin la intervención de ésta ni el menoscabo de la biblioteca para el incremento de la colección propia no produce efectos contrarios a los buenos usos y a la ética profesional del bibliotecario.

\subsection{El bibliotecario como tasador de libros}

De la misma manera, si el bibliotecario es requerido como miembro de la biblioteca para realizar una valoración económica de una pieza o de una colección, no debería efectuarla particularmente obteniendo remuneración en metálico o en especie por ello. Se entiende que esta actividad la realiza en función del puesto que ocupa en el centro. Es diferente si tiene que efectuar este tipo de actividades para la biblioteca, en cuyo caso las realiza como bibliotecario, carente de remuneración, salvo la propia del ejercicio profesional en la Institución. Todo ello no obsta para que se puedan recomendar las herramientas adecuadas para llevar a cabo la autentificación o tasación por los propios medios del que solicita el servicio.

\subsection{El bibliotecario como trabajador exterior}

Los bibliotecarios de fondos especiales y antiguos tienen el mismo derecho que otros profesionales a dedicarse a la investigación personal y el empleo exterior, incluyendo docencia, dictado de conferencias, publicación de trabajos y otras actividades de creación, de acuerdo con las normas de actuación institucional y bibliotecaria existentes, como se ha dicho ya. En estos menesteres no es aceptable el uso de información no pública o de un acceso privilegiado a los fondos, así como el uso privilegiado de las herramientas y recursos de investigación. Pero, por el contrario, no se considera falta ética el uso de los recursos de investigación del centro cuando se empleen en las mismas condiciones que el resto de los usuarios investigadores del mismo. Por consiguiente no se debe utilizar en el domicilio particular del bibliotecario para estos fines ningún objeto o pieza que forme parte de las colecciones de la biblioteca o que se encuentre bajo la custodia de la biblioteca y que no pueda ser empleado normalmente de la misma manera para uso domiciliario por parte del público en general. En estas situaciones, los derechos de propiedad intelectual del autor y de la biblioteca deben quedar a salvo y no confundirse. En cualquier caso, los trabajos realizados fuera de la biblioteca serán considerados como actividad secundaria con respecto al trabajo y responsabilidad de bibliotecario en la biblioteca evitando que esas actividades no interfieran en esta actividad principal sin comprometer ni la reputación de la biblioteca ni la integridad profesional del bibliotecario. En estas actividades exteriores se tenderá a omitir cualquier referencia al puesto ocupado en la biblioteca, puesto que es fácil que se considere a estos profesionales en esas actividades como representativos de la entidad para la que trabajan aunque esa labor sea independiente del centro en cuestión. Parece necesario, para evitar cualquier tipo de conflicto, comunicar a los responsable de la biblioteca cualquier proyecto de empleo exterior u organización de consultoría. Si bien estas circunstancias pueden ser comunes a todo tipo de bibliotecarios, es indudable que debido a las características de los documentos antiguos es más frecuente que los profesionales realicen y difundan investigaciones sobre estos fondos siendo imprescindible el uso de los recursos de la biblioteca en cuestión.

\subsection{El bibliotecario como bibliotecario}

El conocimiento de las actividades de investigación de otros usuarios, donantes o libreros, debido al ejercicio profesional en la biblioteca debe de tener carácter confidencial debiéndose respetar la privacidad de estas informaciones. También este principio es común y extensivo a todos los profesionales.

\section{Aspectos y códigos deontológicos en torno a la biblioteca de fondo antiguo}

La presencia de recomendaciones y códigos para las bibliotecas es abundante, y será de aplicación a aquellas que tienen fondos especiales o fondos antiguos. La importancia de la colección en este caso es primordial. La responsabilidad de la biblioteca con respecto a su conservación y a su difusión según la normativa 
legal y deontológica se constituye como un pilar básico de las actuaciones con respeto a estos fondos. Un segundo pilar es el del desarrollo de la colección y el de su evolución. Y el principal es el de proporcionar un acceso ágil y sin discriminación a la misma.

Con respecto a los documentos debe de especificarse de forma clara la autenticidad de los mismos o las reproducciones facsimilares que contengan, de forma que no quepa duda de que los documentos que se puedan consultar son en efecto los que se ofertan en los catálogos.

\subsection{La colección y el acceso}

La biblioteca es el mediador entre una colección o fondo bibliográfico y unos usuarios. Por tanto, el primer aspecto a considerar es el acceso. El principio de no discriminación de usuarios por cualquier razón es aplicable siempre y sigue los principios generales de la legislación, por tanto no se puede negar el acceso a los fondos tomando como base los méritos académicos o la pertinencia del trabajo de investigación (20). Las limitaciones al acceso solo deben estar justificadas por la salvaguardia de la integridad y seguridad de los fondos o de la colección (21). En manera alguna se deben establecer reservas de materiales para investigadores específicos (22). No menos importante que la actitud de la biblioteca ante los investigadores es la utilización de normas de catalogación aceptadas profesionalmente, comprensibles por los investigadores y la difusión de los contenidos de la forma más libre y abierta posible para que lleguen a todos los lugares, o, lo que es lo mismo, se han de buscar criterios de calidad en el tratamiento de los fondos para que el acceso sea sencillo y no se debe restringir la difusión del contenido de la colección.

\subsection{La custodia de la colección o el fondo}

La responsabilidad que la biblioteca adquiere con respecto a los propios documentos que custodia es la esencia misma de su actividad. Los documentos son la materia prima de la biblioteca.

Los fondos de la biblioteca poseen, además, un componente esencial de conocimiento histórico, ya que reflejan lo que ha interesado a esa institución durante el transcurso del tiempo. Se convierten así en algo más que unidades bibliográficas susceptibles de ser utilizadas, resultando un conjunto que refleja la herencia intelectual de la entidad que los custodia.

Es necesario, en consecuencia, salvaguardar las colecciones y fondos implantando normas para proteger la integridad física de esos materiales contra el robo, el deterioro, la alteración y el daño físico, buscando evitar cualquier daño que pueda producirse en ellos por causa de su conservación, ordenación o almacenamiento o del uso de los mismos (23). Para ello, se establecerán los procedimientos y normas internas necesarias, se evaluaran los procedimientos, se realizarán inspecciones, se preverán las posibles daños causados por catástrofes y robos. No se trata sólo de un principio deontológico sino también de una obligación legal derivada del componente patrimonial del fondo bibliográfico.

\subsection{El desarrollo de las colecciones y el tratamiento de los fondos}

La política de desarrollo de la colección debe estar perfectamente planificada, siendo acorde a los objetivos y actividades de la biblioteca debiendo mantener un dossier sobre cada una de las unidades en lo que respecta a la justificación de la propiedad y de la procedencia, persiguiendo evitar ser víctima de la incorporación de ejemplares previamente substraídos de otras colecciones. Los códigos deontológicos dan mucha importancia al expurgo que presenta problemas muy importantes, especialmente de carácter legal (24). Cuando el ingreso se produce por donación habrá de poner cuidado en que las condiciones sigan unos principios y cláusulas previamente establecidos en la política de adquisiciones de la bibliotecaria, incluyendo cuestiones tales como la autenticación, información a los tasadores, y aportación de información sobre legislación fiscal sobre donaciones.

\subsection{Las bibliotecas y las actividades profesionales sobre el libro antiguo}

La biblioteca puede asesorar sobre la autenticidad o el precio de los libros para quienes deseen efectuar una donación o para particulares, preferentemente ofreciendo obras de referencia, pero solo en calidad de opinión y nunca como valoración profesional. Las bibliotecas no pueden suplir a los profesionales de estas actividades en ellas. Para este mismo fin, en el caso de aconsejar profesionales que efectúen estas labores, se debe de ofrecer un abanico de posibilidades a efectos de evitar la apariencia de connivencia o favoritismo.

En la relación con las librerías deben de llevar todos los asuntos con libreros y vendedores de una forma abierta y ética. La forma de actuación a la hora de pactar posibles pagos fraccionados, el tiempo de disposición de los libros y el procedimiento de actuación ante los libros a examen..., debe de adecuarse a los métodos y 
procedimientos de actuación del resto de los clientes de las librerías.

\section{A modo de conclusión}

El mundo del libro antiguo requiere un tratamiento desde la perspectiva ética profesional perfectamente individualizado con respecto a otros mundo relacionados con el libro, no sólo por su componente patrimonial y por ser los libros antiguos y de colección objetos económicamente costosos, sino porque se tratar de un tipo de documentos sobre los que las opiniones y las actuaciones de expertos influyen en los ámbitos en los que se custodian y comercian, especialmente en los valores y en el precio que poseen esos documentos.

Hay dos ámbitos que se diferencian claramente en torno a este mundo por su preocupación ética: el del comercio del libro antiguo y raro y el de las bibliotecas con fondos antiguos y raros. Ambos mundos han generado códigos deontológicos que inciden especialmente en la exigencia de la determinación exacta de la identidad del documento, ya que esa influencia determina el interés que el propio documento es capaz de suscitar frente al patrimonio, a la investigación o a su comercio.

Lógicamente en el mundo del comercio se incide en la relación de la transacción, mientras que el mundo de las bibliotecas se ocupa de las relaciones del bibliotecario con la biblioteca y las de la biblioteca con el fondo y con sus usuarios.

\section{Notas}

(1) Un caso claro de conflicto deontológico resuelto siguiendo las pautas de los códigos internacionales es el que narra Carlos Clavería Laguarda (2005).

(2) Baste recordar algunos hechos recientes relacionados con el robo y la mutilación de ejemplares: el caso del empresario Iraní que amputó numerosos libros en la British Library en 2008, el de las amputaciones de mapas de la Biblioteca Nacional de España un año antes, el saqueo de la biblioteca del Seminario de Cuenca o la de La Seo de Zaragoza a mediados del siglo pasado, además de falsificaciones de páginas o de autógrafos en ejemplares específicos, como es el caso de las falsificaciones de firmas en el mercado americano de primeras ediciones o falsificaciones de ejemplares completos, como es el caso de algunos "crisolines" de la editorial Aguilar.

(3) Cf. Gaskell, Phillip, Nueva introducción a la bibliografía material, Gijón, Trea, 1999; o Mckerrow, Roland B., Introducción a la bibliografía material, Madrid, Arco Libros, 1998, entre otros muchos.

(4) Esas cuestiones no difieren de las que surgen al tratar los códigos deontológicos bibliotecarios en general. Cf. Entre otros muchos trabajos Bermello Crespo, Luis, Análisis comparativo de 12 códigos de ética bibliotecaria, La Habana : Biblioteca Virtual de las Ciencias de Cuba, 2005-2008. http://www.bibliociencias.cu/gsdl/collect/eventos/index/a ssoc/HASH016c.dir/doc.pdf >, [2010-04]

(5) Vid nota 1.

(6) Ilab Code of Ethics, London, ILAB, ca. 1999-, <http://www.ilab.org/eng/ilab/code.html> [2010-04].

(7) Puede localizarse en: Asociación de Libreros de Viejo y Antiguo de Castilla y León, Libreros de viejo: el portal del libro antiguo, Urueña, Librerosdeviejo.com, 2004<http://www.librerosdeviejo.com/quienes somos.shtml? idboletin=1543\&idseccion=8467> [2010-04] .

(8) La calidad de algunas de estas actuaciones supondrá un interés añadido del ejemplar sobre los que componen el resto de la edición, lo mismo ocurrirá con la trascendencia de los poseedores que dejan rastro en el ejemplar.

(9) Algunas de estas actuaciones son muy complicadas de identificar y pueden dar lugar a la presunción de la existencia de ejemplares únicos de ediciones desconocidas que son difíciles de identificar, aunque no imposibles. Cf. Julián Martín Abad, La valoración del libro: el punto de vista del bibliotecario de fondo antiguo, Madrid, Foro Complutense, Ciclo de Conferencias sobre Bibliofilia y Mercado del Libro, 2004, pp. 10-11 <https://www.ucm.es/BUCM/foa/Conferencias/conferen cia2.pdf > [2010-04] Sobre una edición incunable zaragozana del Lunario de Granollachs impreso por Hurus en 1492.

(10) Vid nota 1.

(12) También denominado Codex Leicester, contiene 36 folios con escritos y dibujos de Leonardo da Vinci. Se denomina Hammer por haber sido adquirido en 1980 por el millonario Armand Hammer procedente de la colección de Lord Leicester (de ahí su otra denominación). Actualmente es propiedad del millonario norteamericano Bill Gates que lo adquirió en una subasta en 1994 por unos veinticinco millones de dólares.

(13) Un ejemplar del De Humani Corporis Fabrica Libri Septem de la primera edición: Basileae, Ex officina loannis Oporini, 1543, coloreado a mano que fue propiedad del emperador que poseía una buena relación de amistad con el autor Andrea Vesalio. Fue vendida en 1998 por más de un millón y medio de dólares.

(14) Mark William Hofmann fue el descubridor del único ejemplar de The Oath of a Freeman, supuestamente impreso en 1639, siendo por un año el impreso más antiguo de las colonias norteamericanas. Se sabía de su existencia verdadera y se conocía su contenido pero se suponía que se habían perdido los cincuenta ejemplares que se confeccionaron. El impreso en cuestión, que fue adquirido por la biblioteca del Congreso de los Estados Unidos por un millón de dólares, resultó ser una falsificación. El caso fue descubierto a raíz del asesinato de la esposa de un comerciante de libros antiguos y el intento de asesinato de otro mediante el procedimiento del paquete bomba del que Hofmann fue acusado y condenado a muerte conmutada por la de cadena perpetua. El número de falsificaciones de Hofmann es importante pero sólo ha reconocido algunas de ellas como tales, y, entre éstas la del The Oath of a Freeman.

(15) Vid nota 9.

(16) Cf. Martín Abad, La valoración del libro, p. 21 en la que trata el desafortunado caso del volumen facticio de José Antonio Conde que contenía cuatro obras médicas editadas en el siglo XVI de cierta rareza y que fue disgregado hacia el año 2.000 , perdiendo los ejempla- 
res disgregados la procedencia y la historia que los había mantenido juntos desde principios del siglo XVI.

(17) Durante un tiempo se han usado diversos sistemas de codificación de precios que permitían al librero conocer el precio por estar indicado en el ejemplar para poderlo ajustar a las características del posible comprador que se interesaba por él

(18) En su segunda edición fueron publicados en el College and Research Library News (C\&RLNews), 54, 4 (1993) y fueron publicadas como separata el año siguiente.

(19) http://www.ambifa.org/wp-content/uploads/codigoetica1.pdf [2010-04]

(20) Art. 44 de la Constitución española de 1978 (BOE de 29 de diciembre de 1978).

(21) Art. 62 del Real Decreto 111/1986, de 10 de enero, de desarrollo parcial de la Ley 16/1985, de 25 de junio, del Patrimonio Histórico Español (BOE de 28 de enero de 1986).

(22) Las normas éticas excluyen el pacto en contrario establecido contractualmente en una donación y recomiendan que no se acepten pactos en esta dirección.

(23) Art. 52 de la Ley 16/1985, de 25 de junio, del Patrimonio Histórico Español (B.O.E. de 29 de junio de 1985).

(24) Cf. Ley 16/1985, de 25 de junio, del Patrimonio Histórico Español (B.O.E. de 29 de junio de 1985).

\section{Referencias}

Asociación de Libreros de Viejo y Antiguo de Castilla y León, Libreros de viejo: el portal del libro antiguo, Urueña: Librerosdeviejo.com, 2004. http://www.librerosde viejo.com/quienes_somos.shtml?idboletin=1543\&idseccion $=8467(2010-0 \overline{4})$

Bermello Crespo, Luis, Análisis comparativo de 12 códigos de ética bibliotecaria, La Habana: Biblioteca Virtual de las Ciencias de Cuba, 2005-2008. http://www. bibliociencias.cu/gsdl/collect/eventos/index/assoc/HASH016c.dir/d oc.pdf (2010-04)

Clavería Laguarda, Carlos, «Criterios objetivos y subjetivos de tasación» // Pedraza Gracia, Manuel José (ed.). Tasación, valoración y comercio del libro antiguo (textos y materiales): Jaca 2-6 de septiembre de 2002, Zaragoza: Prensas Universitarias de Zaragoza, 2002. 167-179.

Clavería Laguarda, Carlos, «El espantoso caso del "Etymologicum magnum graecum": de cuanto vale un libro o "de misera humanae conditionis"»// Pedraza Gracia, Manuel José (ed.). Valoración y tasación del libro antiguo (textos y materiales): cuarto Curso-Taller sobre Comercio y Tasación del Libro Antiguo: Jaca, 5-9 de septiembre de 2005, Zaragoza: Prensas Universitarias de Zaragoza, 2005. 149-161.

Constitución española de 27 de diciembre de 1978 (BOE n. 311 de 29 de diciembre de 1978). http:// www.boe.es/aeboe/consultas/bases_datos/doc.php?id= BOE-A-1978-31229 (2010-04)

Gaskell, Phillip, Nueva introducción a la bibliografía material, Gijón, Trea, 1999.

ILAB: International League of Antiquarian Booksellers, Ilab Code of Ethics, London, ILAB, ca. 1999-, http:// www.ilab.org/eng/ilab/code.html (2010-04).

Ley 16/1985, de 25 de junio, del Patrimonio Histórico Español (B.O.E. n. 155 de 29 de junio de 1985). <http://noticias.juridicas.com/base_datos/Admin/l161985.html> (2010-04).
López López, Pedro, «La formación ciudadana en Biblioteconomía y Documentación: España y el Espacio Europeo de Educación Superior» // Gimeno Perelló, J.; López López, P.; Morillo Calero, M.J. De volcanes Ilena: biblioteca y compromiso social. Gijón: Trea, 2007.

Martín Abad, Julián, La valoración del libro: el punto de vista del bibliotecario de fondo antiguo, Madrid, Foro Complutense, Ciclo de Conferencias sobre Bibliofilia y Mercado del Libro, 2004, <https://www.ucm.es/BUCM/foa /Conferencias/conferencia2.pdf > (2010-04).

Mckerrow, Roland B. Introducción a la bibliografía material, Madrid, Arco Libros, 1998.

Normas de Conducta Ética para Bibliotecarios de Libros Raros, Manuscritos, y Fondos Especiales, con Directrices para la Práctica Institucional en Apoyo de las Normas, $2^{a}$ edición, 1992. Traducción por el Grupo de Trabajo sobre Patrimonio Bibliográfico de REBIUN. http://www.ambifa.org/wp-content/uploads/codigoetica1.pdf (2010-04).

Pérez Pulido, Margarita, «Códigos de ética de los bibliotecarios y otros profesionales de la información: comentario y análisis comparativo» // Boletín de la ANABAD. 51:3 (2001) 37-58

Real Decreto 111/1986, de 10 de enero, de desarrollo parcial de la Ley 16/1985, de 25 de junio, del Patrimonio Histórico Español (B.O.E. n. 24 de 28 de enero de 1986). Consultado en febrero de 2010. <http://noticias.juridicas.com/base datos/Admin/rd1111986.html> (2010-04).

Samek, Toni, Librarianship and Human Rights: A twenty-first century guide, Oxford: Changos, 2007.

Recibido: 25-04-2010. Revisado: 30-06-010.

Aceptado: 06-07-2110. 